Las figuras laterales de San Pedro y San Benito también recuerdan el mundo del esculto por su sobriedad y su firme apostura, además hay detalles que vemos en obras del autor madrileño, la barba del San Pedro recuerda en su tratamiento la manera blanda y sinuosa de la talla del profeta Elías, su rebuscada manera de llevar el libro recuerda al San Antonio de la fachada del Hospital de los Portugueses en Madrid y la policromía de sus ropas, aquí con colores planos, adornada con rameados dorados aparece en el San Marcos de Martín Muñoz de las Posadas. El San Benito resulta, sin embargo, más movido que los Santos frailes del Monasterio de San Plácido, en un tratamiento más barroco de su figura y curiosamente la barba se trabaja de modo muy distinto a la del San Elías que aquí describimos, a mechones largos y sueltos.

Aunque de modo indirecto, otras dos circunstancias apuntan al mundo madrileño en el que se desenvuelve Pereira. El pintor Francisco Camilo que policroma varias obras del escultor y con quien tuvo además relación de amistad también trabaja para este templo. Para él contrató una serie de lienzos de los que sólo se conservan los dos que presiden los retablos laterales cercanos al presbiterio ${ }^{24}$. Y por último, la fachada de la iglesia está presidida por una imagen de la Inmaculada, realizada en piedra de Tamajón, de formas macizas y carente en absoluto de gracia, que documentalmente sabemos realiza el escultor Manuel Correa ${ }^{25}$ quien colabora con Pereira y en ocasiones se hace cargo de alguna obra contratada por el maestro que éste se ve obligado a traspasar ${ }^{26}$.

JuAN Nicolau CASTRO Doctor en Historia del Arte

\title{
LAS COLGADURAS DE SEDA DEL SALÓN DE MARÍA LUISA EN LA CASA DEL LABRADOR
}

Si una de las estancias más bellas y espectaculares de la Casa del Labrador de Aranjuez es, sin duda, la del «Salón de María Luisa», se debe en gran medida a las colgaduras con que se hallan vestidas sus paredes, se adornan sus ventanas ys puertas y se tapizan sus muebles (Figs. 26-27).

Ya desde antiguo, se reconoce el mérito de estos tejidos y así se reseña en la Historia descriptiva del Real Sitio de Aranjuez, escrita por Cándido López y Malta quien al hablar de este salón, no duda en calificarlo de «sobresaliente», especificando que «sus paredes están todas forradas de sedería esquisita, bordada toda de vistas de italia y paisajes de composición, de un mérito tal que no acertaría a describirlo la mejor cortada pluma» ${ }^{\text {. }}$

Tan excepcional colgadura fue realizada en la mejor y más prestigiosa manufactura sedera de la Europa de finales del siglo XVIII, la de Camille Pernon, que ya había intervenido en la decoración de diferentes estancias en El Pardo, El Escorial y Madrid y a quien se deben las mejores sederías de este palacete de recreo ${ }^{2}$.

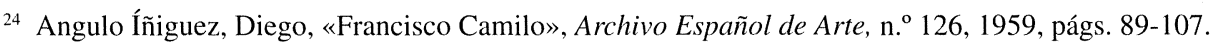

${ }^{25}$ Suárez Quevedo, Diego, o.c., pág. 165.

${ }^{26}$ Esto ocurre, por ejemplo, con la escultura del retablo de la iglesia de Torrejón de Velasco, contratado por Pereira y traspasado a Manuel Correa. Ver Mercedes Agulló, «Manuel Pereira: Aportación documental», pág. 276.

' C. López y Malta, Historia descriptiva del Real Sitio de Aranjuez, Aranjuez, 1868, págs. 312 - 313.

2 Está próximo a publicarse el estudio que a lo largo de varios años he venido elaborando sobre todos y cada uno de los textiles que la fábrica de Pernon hizo para la Casa del Labrador. En él se ofrecerá también información sobre los autores de las vistas que sirvieron de modelo para los bordados que decoran las paredes de esta estancia y del salón de billar.
} 
Hace algunos años Juan José Junquera publicó una importante documentación relativa a todos estos trabajos ${ }^{3}$ pero, hasta el momento no se había localizado la factura de los tejidos del «Salón de María Luisa», que el propio Camille Pernon presentó en Madrid el 11 de octubre de $1803^{4}$, acompañada de una carta a Felipe Martinez de Viergol, Jefe de las Reales Casas de Campo. Estos documentos ofrecen interesante información tanto sobre las piezas que componen la sedería mural, las cortinas y el tejido para vestir los taburetes de la sala, como sobre las incidencias de su encargo, fabricación, embalaje, envío a España, derechos de aduana y pago.

El fabricante lyonés, que en aquellas fechas estaba asociado con Enrique Ravi ${ }^{5}$, no recibió el encargo directamente sino por medio de Juan Antonio Miquel, cobrando un adelanto de 300.000 reales de mano de Miguel Gay. Conviene aclarar que estos dos personajes eran fabricantes y comerciantes de tejidos de seda de la ciudad de Valencia, que en aquel momento, junto con las manufacturas establecidas en Toledo y la Real Fábrica de Talavera de la Reina, eran los centros productores de sederías más importantes de España.

Los documentos firmados por Pernon también especifican que ese adelanto le había sido entregado por «los señores Miguel Gay y $\mathrm{C}^{\mathrm{a}}$ » ya que el fabricante valenciano había recibido 580.000 reales «a cuenta de las demás obras que de Real Orden están a cargo de la Real Fábrica de dichos señores». Este es un ejemplo claro de que las relaciones entre Lyon y Valencia no se limitaron a la mera copia de tejidos franceses por parte de los sederos valencianos, sino que existió una colaboración comercial estrecha entre ambos, mas importante de lo que han señalado algunos autores ${ }^{6}$.

El encargo fue entregándose por partes, según se desprende de la citada factura. El 12 de mayo de 1802, salió de la fábrica la primera remesa de tejidos, en un cajón marcado «FMV n. ${ }^{\circ}$ $262{ }^{7}$ para ser «presentada por Juan Antonio Miguel». Se componía de dos paños con tres cuadros bordados cada uno, que posiblemente servirían de muestra para obtener el visto bueno definitivo del rey y así proseguir con el encargo sin ningún tipo de trabas. El resto de las telas, fueron saliendo de Lyon paulatinamente . El primer grupo grande partió hacia España, vía Bayona, el 17 de diciembre siguiente. Las piezas estaban distribuidas en dos cajones marcados «SMC n. ${ }^{\circ}$ $1 » \mathrm{y}$ «SMC n. ${ }^{\circ} 2 »$, embalados «en doble tela grasa» para aislarlos de la humedad. Los tejidos estaban enrollados en tablillas y cartones y envueltos en papel de seda y guata de algodón. De forma similar se mandaron las otras tres remesas que partieron el 1 de marzo de 1803 (cajones 3 y 4), el 20 de julio siguiente (cajones 5, 6 y 7) y la última (cajón 9) de la que no se menciona la fecha de salida, pero de la que se dice que aún no había llegado a Madrid el 1 de octubre de aquel año, fecha en la que, como hemos dicho, Pernon firmó la factura.

Sin duda, lo más llamativo del conjunto es la decoración mural. Se trata de una colgadura tejida de fondo blanco imitando mármol, con motivos de trofeos de armas en color bronce y oro

\footnotetext{
${ }^{3}$ Hay que decir que el profesor Junquera ha sido uno de los primeros autores españoles que ha valorado acertadamente la importancia de los trabajos de este fabricante lyonés y por ello es obligada la consulta de su obra La decoración y el mobiliario de los palacios de Carlos IV, (Madrid, 1979) para todo aquel que quiera profundizar en el tema.

${ }^{4}$ Cfr. Archivo General de Palacio, Reinados, Carlos IV, Casa, leg. 186. En el mismo legajo, se encuentra la documentación que acredita el paso de los tejidos por las diferentes aduanas y los distintos mandamientos de pago.

${ }_{5}^{5}$ Sobre la trayectoria profesional del prestigioso fabricante lyonés, puede consultarse A. Poidebard y J. Chatel, Camille Pernon, fabricant de soieries a Lyon sous Louis XVI et Napoleon ler. 1753-1808, Lyon, 1912 y C. Gastinel-Cou$\mathrm{ral}$ «Notes et documents», Soieries de Lyon. Commandes royales au XVIIIe siècle. 1730-1800, págs. 69-75 y 98-101.

${ }^{6}$ Sobre las relaciones entre los fabricantes valencianos y la manufactura lyonesa, puede consultarse P. Benito García y A. García Sanz, «Noticias sobre algunos encargos de los Reyes de España a las fábricas sederas de Valencia en el siglo XVIII» en Arte de la seda en la Valencia del siglo XVIII, Valencia, 1997, págs. 107-123 y en las fichas del mismo catálogo que elaboré de algunas de estas piezas valencianas (págs. 302-317).

7 Supongo que se tratarán de las iniciales de Felipe Martínez de Viergol, a quién debía de ir dirigido.
} 
que enmarcan octógonos bordados con paisajes ${ }^{8}$. El conjunto se completa con una serie de cenefas «tejidas a dos caminos, espolinado seda broncé y oro, «ecusones» ${ }^{9}$ para los ángulos de los paños, cuatro sobreventanas también tejidas y cuatro grandes sobrepuertas bordadas que representan las cuatro estaciones ${ }^{10}$. Para tapar la costura de unión entre las sobrepuertas y el resto de la sedería del muro, se envió una cenefa a cuatro caminos de fondo punzó espolinada en oro.

La realización de un encargo tan complejo y caro exigía una perfecta planificación y así se hizo, a juzgar por las indicaciones que figuran en el documento. Las paredes se diferenciaban por letras y números ${ }^{11}$ : B2, D3, F4 y H1, para que en Aranjuez no hubiera problemas a la hora de colocar en ellas las piezas de tela correspondientes a cada muro. Así por ejemplo, en la pared B2 se colocó la pieza de mayor tamaño que se componía de 7 paños con 24 cuadros bordados, en el testero central y dos paños sueltos con tres paisajes bordados cada uno en los testeros laterales. Con estas indicaciones, se reconoce fácilmente que al hablar de la pared B2, se hace referencia a la que se encuentra enfrente de la chimenea. Las mismas certeras identificaciones se pueden efectuar con el resto de los muros y de las telas.

En lo que se refiere a las cortinas de ventanas y puertas, llegaron sin confeccionar, enviándose para su campo central una «tela adamascada blanca doble...punto gros de tours». Se trataba de una bellísima seda decorada con una doble palmeta de gran tamaño y cuyo modelo figura en el libro de patrones del fabricante lyonés, bajo la anotación «Damas fond blanc, Dessin des Rideaux Du Grand Meuble Du Roy D’Espagne» ${ }^{12}$. Según puede verse en antiguas fotografías de la Casa del Labrador, el sobrante de este tejido fue empleado para tapizar los muebles de asiento del Gabinete de Platino ${ }^{13}$. Las cuatro sobreventanas se cubrieron con unas anchísimas cenefas espolinadas en color bronce con motivos de «corona de laurel y olivar»

Para el adorno perimetral de las cortinas se enviaron una «Senefa (sic) a dos caminos»y «146 ecusones» todo espolinado en oro sobre un fondo color punzó. El modelo de la cenefa, un diseño de palmetas en oro enlazadas entre sí y bordeadas por cenefillas marginales de pequeños contarios de hojas y tréboles, también figura en el libro de patrones con una curiosa anotación: «Bordure 2 chemins, f.ponceau, Broché or, pour les Rideau Du Mble. Du Roy D’Esp. de Gay» ${ }^{14}$; nuevamente, la figura de uno de los dos fabricantes valencianos que intervinieron en este encargo. Sin embargo, el modelo de los cuadradillos o ecusones, las iniciales de Carlos IV y Maria Luisa, no aparece reseñado en el libro de patrones del fabricante.

${ }^{8}$ Los paisajes, que fueron bordados uno a uno a mano, y no a máquina como se ha dicho, van cosidos sobrepuestos encima del tejido de imitación de mármol. La realización de estas piezas se hizo por separado: en el telar, el tejido de base que era un lampás espolinado, y en tambores todos y cada uno de los bordados, siendo un trabajo posterior la composición del conjunto. En Lyon, aún se conserva alguna de las piezas de tela que carecen de bordados, pudiendo apreciarse el fondo de raso blanco que en las piezas de Aranjuez queda oculto por los bordados. Cfr. Commandes..., pág. 131, n. ${ }^{\circ} 84$.

${ }^{9}$ Una»cenefa a dos caminos» 0 «a dos alas» es aquella que se ha tejido doble en un mismo paño; dependiendo de su ancho se pueden tejer en una misma tela varias cenefas, normalmente entre una y cuatro, que luego no hay más que recortar para su utilización. Era una forma de ahorrar esfuerzo y seda. Cuando se habla de los ecusones se refiere a los cuadradillos que decoran los ángulos de los entelados de pared o de las cortinas. En este caso, aunque la factura no espcifica cómo fueron tejidos, se sabe por algunos restos que se han conservado en los almacenes del Palacio Real de Madrid, que también se tejieron a dos caminos.

${ }^{10}$ Cenefas y sobrepuertas se enviaron por separado para facilitar el trabajo de su colocación en Aranjuez.

$"$ A Lyon se debieron mandar dibujos de alzados de las distintas paredes con sus medidas para poder calcular el número de piezas de tela que debián tejerse y la cantidad de paisajes que debían bordarse y posteriormente componer todo de tal forma que no faltase ni sobrase nada y las piezas llegasen a Aranjuez dispuestas para ser encajadas perfectamente en cada hueco.

${ }^{12}$ Lyon. Archivo Tassinari et Chatel. Libre des patrons et prix des etoffées (sic) pour meubles, asiento n. ${ }^{\circ} 1602$.

${ }_{13}$ Un estudio completo sobre este tejido y sobre la decoración del Gabinete Platino puede consultarse en Ch. GastinelCoural, «Le Cabinet de platine de la Casa del Labrador à Aranjuez. Documents inédits», Bulletin de la Société de l'Histoire de l'Art français, sesión 1993, París, 1994, págs. 181-205.

${ }^{14}$ Lyon. Archivo Tassinari et Chatel, ob. cit., asiento 1595. No es esta la única vez que el apellido Gay se menciona en el libro, sino que aparece escrito en numerosos modelos. 


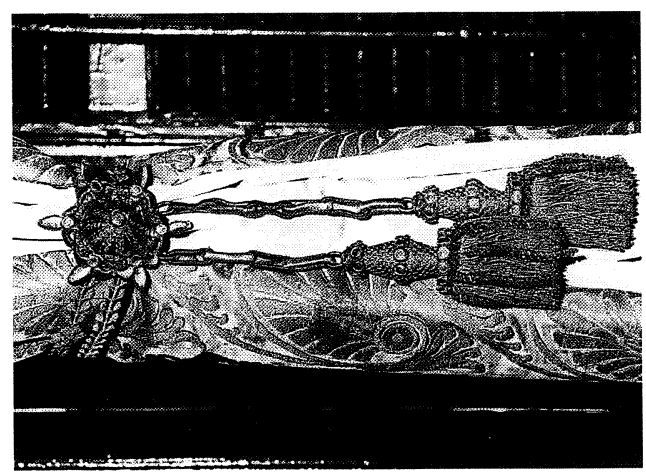

ง
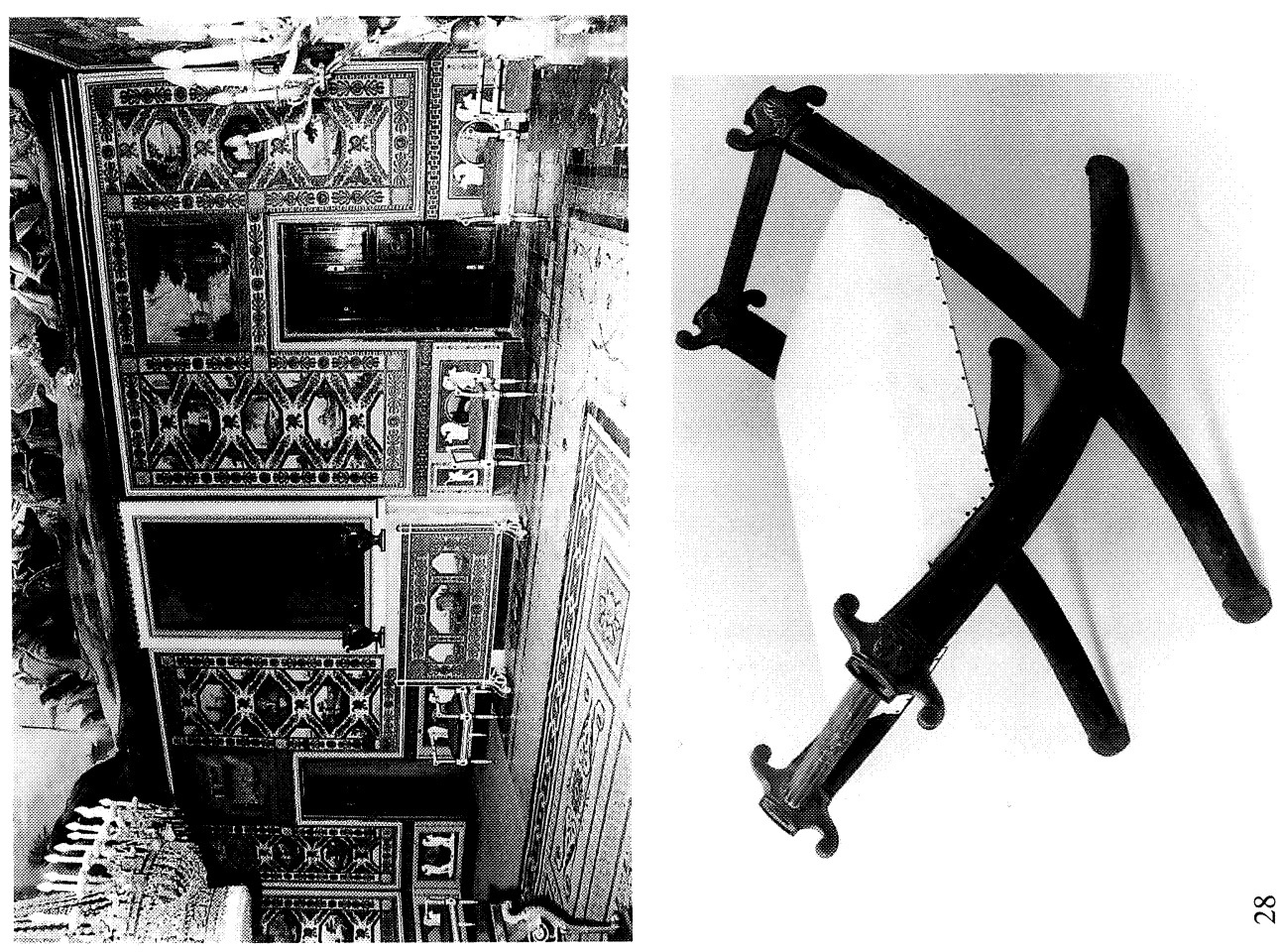

ते

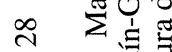

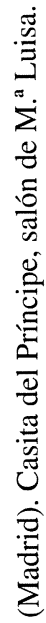

产

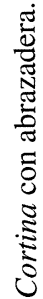

8

紊

$\lambda$

ํํㅇㅝㅝ

ص

몰

ए

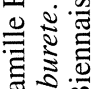

Uే

$\therefore \dot{0}$

䨔 跑

象.

뜔 뽀

密

悹春守

त势壳

ते

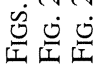


La documentación hallada no menciona las bellas abrazaderas de pasamanería que servían para recoger las cortinas ${ }^{15}$. Confeccionadas con la misma tela de la cenefa, se adornan con una una gran flor de la que pende una cadena en hilo de oro rematada en dos borlones. Es de suponer que este trabajo fuera realizado en España por los pasamaneros de la Real Casa, como ya había ocurrido en otras ocasiones ${ }^{16}$.

Por su parte, el tejido para los taburetes era igualmente un espolinado de oro en el que, sobre un campo de «raso gris acero», destaca en relieve ${ }^{17}$ un «dibujo de palmas» que alberga las iniciales de los reyes en el interior ${ }^{18}$. Para el perímetro de estos muebles de asiento se enviaron fajas con el campo de tafetán también color punzó, bordadas a dos caras con un dibujo de palmas y estrellas.

En la factura no se encuentra ninguna referencia al tejido de la pantalla de chimenea de la sala. Es posible que para realizar esta guarnición se utilizran los paños que presentó Juan Antonio Miguel y que son los únicos sobre los que no se indica su concreta ubicación.

Sin embargo si que se reseña otro mueble realizado por Biennais y comprado por Pernon en París, el 22 de pradial del año XI (11 de junio de 1803) ${ }^{19}$. Se trataba, según se desprende de la factura del fabricante que Pernon adjuntó a la suya, de un precioso taburete de caoba con adornos de bronce, formado por cuatro sables decorados en el centro con escudos que enmarcaban las figuras de Minerva y Marte; las empuñaduras eran de ébano y estaban decoradas con cabezas de león; en los rombos que formaban la unión de los sables, aparecían cabezas de Medusa y la unión de las piezas se efectuaba por medio de manojos de tallos liados con cintas (Figs. 28-29).

Este mueble, que se conserva en los almacenes del Palacio Real de Madrid ${ }^{20}$, es un bello ejemplo de una faceta poco estudiada pero, sin duda, muy interesante del sedero lyonés: su actividad como intermediario en la compra de mobiliario y objetos artísticos de todo tipo con destino a la corte española. De esta manera los gustos de Pernon se extendían ejerciendo una influencia mucho más sutil al conseguir armonizar ambientes dentro de una común sensibildiad.

Pilar BENITO GARCíA ${ }^{21}$ Patrimonio Nacional

\footnotetext{
15 Durante muchos años estas abrazaderas no han estado colocadas en la Casa del Labrador. Hace escasos meses pude localizarlas en el almacén de telas del Palacio Real de Madrid, en un excelente estado de conservación, por lo que me inclino a pensar que debieron cumplir su misión durante muy poco tiempo.

${ }^{16}$ Cfr. P. Benito García, «Camille Pernon y el tocador de la Reina María Luisa en el Palacio Real de Madrid», Reales Sitios, 116, 1993, págs. 17-24.

17 En la factura se habla de «espoliando relevé». Aunque la factura está redactada en español, algunas palabras aparecen en francés.

18 Lyon. Archivo Tassinari et Chatel, ob. cit., asiento 1619. Aunque en el libro figura una anotación similar a las anteriores indicando que se trataba de un modelo especial para el rey de España, en el pequeño apunte a pluma no aparecen las iniciales de Carlos IV y María Luisa, sino una media luna; Según A. Poidebard y J. Chatel (ob. cit., pág. 46 y pl. XXIV), se debe a que fue reproducido para «Su Alteza el Sultán».

19 Sobre Martin-Guillaume Biennais y su famosa tienda establecida en el número 119 de la parisina calle de SaintHonoré bajo el nombre de «Au singe violet», baste decir que adquirió una enorme reputación, llegando a ser uno de los artífices más caros de la capital francesa y uno de los preferidos de Napoleón y de su entorno.

${ }^{20}$ Número de inventario del Patrimonio Nacional 10081273. Por desgracia ha perdido gran parte de los adornos de bronce asi como las empuñaduras de ébano. bajo. ${ }^{1}$

${ }^{21}$ Quiero agradecer a Alvar González-Palacios la gran ayuda que me han prestado durante la elaboración de este tra-
} 